Environment, Biodiversity \& Soil Security
(EBSS)
http://jenvbs.journals.ekb.eg//

\title{
The Living Cells and Elemental Synthesis: New Insights
}

Ayman M. El-Ghamry ${ }^{*}$, Noura El-Ahmady El-Naggar ${ }^{2}$, Ahmed A. Mosa ${ }^{1}$, Ayman Y. El-Khateeb ${ }^{3}$, El-Metwally M. Selim ${ }^{4}$, Haroun M. AboShama ${ }^{5}$, Ahmed M. El-Sawah ${ }^{6}$ and Hassan El-Ramady ${ }^{7}$

${ }^{1}$ Soils Dept., Faculty of Agriculture, Mansoura University, 35516Mansoura, Egypt.

${ }^{2}$ Department of Bioprocess Development, Genetic Engineering and Biotechnology Research Institute, City of Scientific Research and Technological Applications (SRTACity), Alexandria, 21934, Egypt.

${ }^{3}$ Agricultural Chemistry Dept., Faculty of Agriculture, Mansoura University, 35516

Mansoura, Egypt.

${ }^{4}$ Soils Dept., Faculty of Agriculture, Damietta University, 34517 Damietta, Egypt.

${ }^{5}$ Plant Biotechnology Dept., Genetic Engineering and, Biotechnology Institute, Sadat City University, 32958 Sadat, Egypt.

${ }^{6}$ Agricultural Microbiology Dept., Faculty of Agriculture, Mansoura University, 35516 Mansoura, Egypt.

${ }^{7}$ Soil and Water Dept., Faculty of Agriculture, Kafrelsheikh Uni., 33516 Kafr ElSheikh, Egypt.

$\mathbf{T}$ HE GENERATION of new elements inside living cells, either by nuclear fusion or nuclear fission is questionable. Nuclear fusion theory can interpret the increase of an element or reduction of another one following the dissociationof the atomic nucleus of some elements and recoordination of new integrated nuclei, which surrounded by electrons to neutralize protons of nucleus. To proof our hypothesis, in vitro microcosm investigations were carried out using two microbial stains (Bacillus amyloliquefaciens MN592674B and Escherichia coli), which spiked with seven trace elements ( $\mathrm{Ti}, \mathrm{V}, \mathrm{Co}, \mathrm{Ni}, \mathrm{Se}, \mathrm{Mo}$, and B) in a closed system. Total trace element concentrations were determined using Inductivity Coupled Plasma Optical Emission Spectrometry (ICP-OES) at the end of inoculation experiment. Some trace elements (e.g. Se, V and Ni) showed increments, others (e.g. Ti and B) showed reductions; however, some trace elements such asAg, B and Cdvanished completely from the microbial media. The addition of $\mathrm{V}, \mathrm{Co}, \mathrm{Ni}, \mathrm{Se}, \mathrm{Mo}$ and $\mathrm{B}$ to $\mathrm{B}$. amyloliquefaciens culture medium enhanced Bismuth (Bi) bioforming.This finding was also supported by Energy Eispersive X-ray Spectroscopy (EDS) data, which showed substantial alterations in metals distribution in the outersphere surfaces as affected by the microbial strain and the spiked elements. In this regard, trace elements transformation differed greatly among bacterial strains. Findings from this investigation provide insights for understanding elemental transformations in the living cells. Further studies are urgent and needed for more insights concerning this vital theme.

Keywords: Bacillus amyloliquefaciens, Escherichia coli, Trace elements, Nuclear fusion.

\footnotetext{
*Corresponding author : E-mail: aymanelghamry@mans.edu.eg

Authors' e-mails: ${ }^{2}$ nouraalahmady@yahoo.com; ' ${ }^{1}$ ahmedmosa@mans.edu.eg

3aymanco@mans.edu.eg; ${ }^{3}$ eselim2016@du.edu.eg;

5haroun.aboushama@gebri.usc.edu.eg; ${ }^{6}$ ahmedelsawah89@mans.edu.eg

7hassan.elramady@agr.kfs.edu.eg;

Received: 27/1/2021; Accepted: 22/2/2021

DOI: $10.21608 /$ jenvbs.2021.60183.1128

C2021 National Information and Documentation Center (NIDOC)
} 


\section{Introduction}

The law of mass conservation is very important for understanding chemical reactions occurred in the earth. This traditional law states that the quantity of matter in the system remains constant over time in any system that is closed to the transference of matter and energy (in and out). A brief way to explain this law is to say that the quantity of matter in the system is preserved (Poulsen, 2010). It is well known that the law of conservation ofmass assumes that "mass not being produced or lost in chemical reactions". This means that the mass cannot be disappeared in chemical reaction but it can be transformed into another form. Consequently, a question has arised surrounding the behavior of elements inside the living cells: Does the behavior of elements inside the living cells including presence, disappearance, increasing and reduction follow this law?

Cells are very similar to the sophisticated factories as the cell divisions and their labor are quite similar to that found in these factories. Signs on that, all factories have their own external walls to provide the first protection, and other internal walls that provide a separated work area. Cells have some kinds of production lines for assimilates transfer and special managerial departments to decide the synthesis of special products. Additionally, they have a processing department for wrapping/packaging and shipping. During the manufacturing process, the cell has a communication system to order/deliver the components it needs and power supplies to provide the energy for the complicated processes inside cells (Waters and Bassler, 2005).

Living cells are able to perform complicated reactions similar to the most sophisticated factories. For sessence, microorganisms are capable of conducting complex reactions close to the most sophisticated factories. For example, certain bacteria (e.g., Rhizobia, Bradyrhizobia, and Azotobacter) can fix the atmospheric nitrogen whether symbiotically or non-symbiotically in the same way as the most complicated nitrogen fertilizers reactors (Gage 2004). Furthermore, these microorganisms have a high ability to produce enzymes, hormones, antibiotics, organic acids, and other active compounds, which are difficult to be synthesized using sophisticated reactors (Cao et al. 2020 and Pham et al. 2019). The use of microorganisms, especially bacteria, in the production of natural products has been newly headed as it is easy to manipulate, highly productive, availability of genetic tools, and deep knowledge of its physiology (Pham et al., 2019). Cell factory design performance and effective transition from laboratory to large-scale commercial production relies on a multi-scale workflow that integrates many experimental and computational capabilities during both up and down stream processes (Gustavsson and Lee, 2016). Progress with many of these capabilities in recent years has raised realistic prospects for a wide deployment of bio-production for a wide spectrum of chemicals.

The inoculation of microbial organisms is able to produce hormones and antioxidants ${ }^{7}$ (El-Ghamry et al. 2018). In addition, microbial inoculation is able to provide several biological processes (nitrogen fixation, increasing the availability of macro- and micro-nutrients, and decomposition of organic materials). When organisms exist either in nature or added as bio-fertilizer, they are capable of turning a large part of the elements of the case of nanoparticles. Hence, the importance of living organisms in the soils also comes from their ability to transform the original form of elements into the nano form. Thebioreactor is the cornerstone of every biochemical process for the production of a broad variety of useful biological products by using enzymes, mammalian, microbial or plant cell systems. In the particular cell system, a wellbuilt bioreactor is mainly designed to provide a regulated environment to maximize cellular growth and/or product formation (Najafpour, 2007).

Microorganisms are the oldest creature existed on earth since for around 3.5 billion years. Microorganisms are evolving complicated relationships together with humans since the start of human life on the earth (around six million years) (Faust et al. 2012 and Dill-McFarland et al. 2019). For instance, it has been considered that there are about 100 trillion cells harbored by the human body. In fact, the human body is a home of trillions of bacteria, archaea, fungi, and viruses. These microbes belong to different collective communities called "microbiome" (Ursell et al. 2012). The human microbiome has a diverse genetic constitution. The presence of microbiome in human life is responsible for immunity and the functional entity that influences metabolism and drug interactions modulation. Microbiome protects the human body (e.g., skin, respiratory system, and digestive gut) from several potential diseases (Grice and Segre, 2012). More recently, it was repoted that microbiome has a potential for for explaining disparity of COVID 19 mortality (Kumar and Chander 2020). 
Humans and microbes rely on these interactions to grow and stay healthy and there are several species of microbiomecoexisted in human body to maximize its induced immunity (Grice and Segre 2012; Dethlefsen et al. 2007; Kumar and Chordia 2017). Prokaryotes have been present on Earth for at least 3.5 billion years and appear to be the most productive life-form based on total abundance and metabolic velocity. During that period, there were 92 naturally occurring ionic elements that microbes could have the ability to interact with ${ }^{13}$ (Ball, 2002); the transuranic elements are generated largely through anthropogenic processes of nuclear reactions, and most of them have short lifespan. Furthermore, new biological requirements for specific elements such as Bismuth, Cadmium, Barium, Strontium and Boron are likely to be found based on the relatively recent results. With regard to microbial genomics, the new genes in newly sequenced microbes can do more than encode another phosphatase or kinase, but it can be used instead in new and wonderful environmental interactions to human, but is known to prokaryotes for many years (Fig. 1; Wackett et al. 2004).
Nuclear fusion and nuclear fission were also evidenced to generate new elements to complete the periodic table although the final list of periodic Table is contested by some. In an experiment at SHIP, GSI Darmstadt, the new element "111" was created and it was unambiguously identified. Three nuclei of the isotope ${ }^{272} 111$ were observed in irradiations of ${ }^{209} \mathrm{Bi}$ targets with ${ }^{64} \mathrm{Ni}$ projectiles of $318 \mathrm{MeV}$ and $320 \mathrm{MeV}$ energy. In addition, in cold fusion reactions, the new elements of $\mathrm{Z}=107$ to 112 were synthesized based on bismuth and lead targets. The key physical concepts are presented that led to the application of this type of reaction in research experiments for creation of new elements (Hofmann et al., 1995; Hofmann et al. 1996; Hofmann 2011). Consequently, it worth noting that bacteria as a living organism occupy the earth and the elements are the constitutions of this earth. Given the fact that the cell is the smallest unit of the living organisms and the atom is the smallest unit of the element and the living organisms need elements for its life, there must be a strong relation between the cell and the element (Schröder et al. 2008; Bischof and Del Giudice 2013 and Šmajs, 2015).

\section{A}

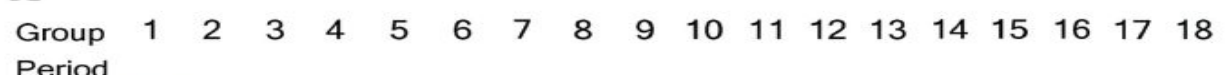

Period

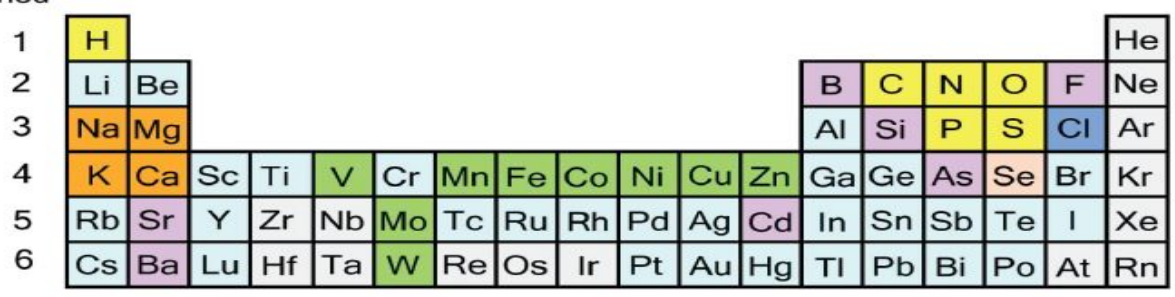

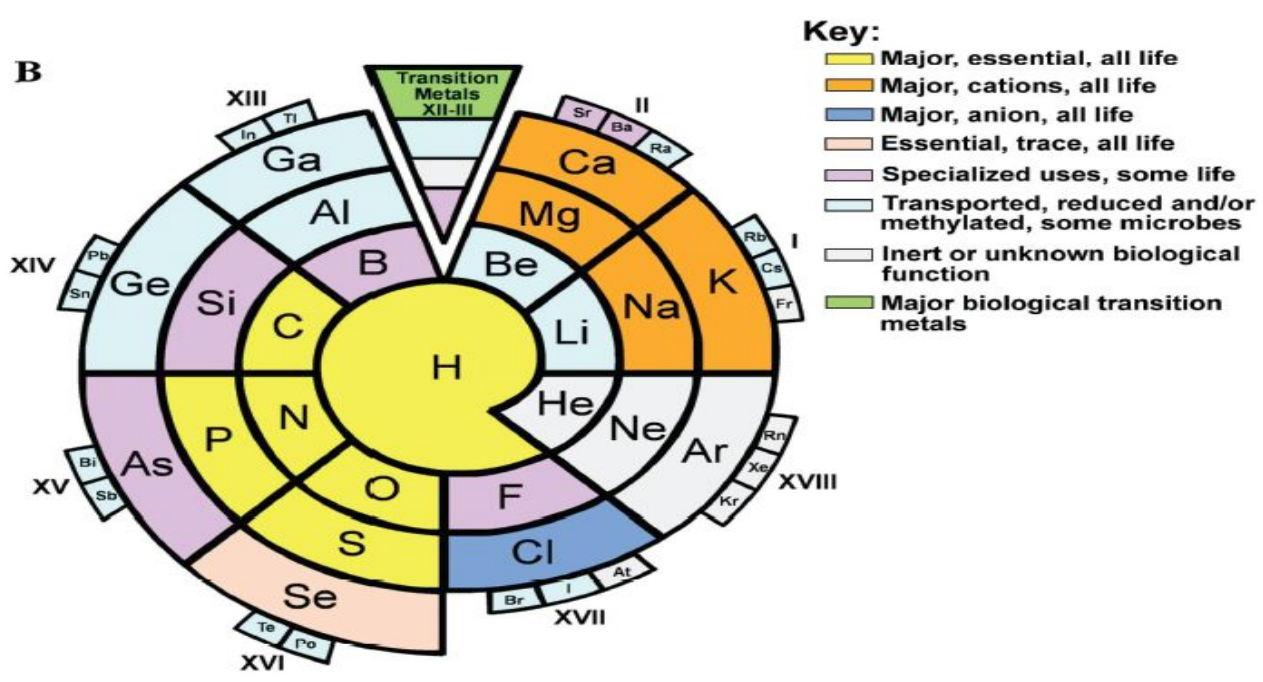

Fig. 1. Periodic elementary representationsamy include: (A) traditional Table with linear rows and columns; for clarity of presentation, the lanthanide and actinide elements present in the online edition were omitted and (B) spiral description of the elements clustering elements common in the biological pathways (Wackett et al. 2004) 
The main aims of this research are to (i) explain the role of the cell in the synthesis of elements through other elements, (ii) identify that the cell has a bioreactor works as nuclear reactor, (iii) proof that the change of nuclei in atoms not only occurs through fission or fusion; however, there is another method depends on the nuclear adhesion to create the nuclei of new elements, (vi) proof that the cell alters in its synthetases among different cells and organisms as the cell according to its exact needs, (V) proof that the addition of trace elements has auxiliary roles in changing the elements as catalyst, and (iv) proof that the cell synthetases is not easy to be created because the cell uses a mixture of elements in different sources (fission, fusion and adhesion elements).

\section{Materials and Methods}

To elucidate the aforementioned aims of this study, the experimental study was carried out in the experimental labs of Faculty of Agriculture, Mansoura University: (i) Soil Fertility and Fertilizers Quality Control (accredited Lab under ISO 17025), (ii) Electron Microscopy Unit, (iii) Agricultural Microbiology Lab (vi) and Agricultural Chemistry Lab.

\section{Microorganisms used in this study}

Bacillus amyloliquefaciens MN592674B was obtained from Botany Department, Faculty of Science, Mansoura University, Egypt. Escherichia coli was obtained from Microbiology Department, Faculty of Agriculture, Mansoura University, Egypt.

Microbial environment: composition and its growth

Agar slants were inoculated with the tested bacterial strains (B. amyloliquefaciens MN592674B and E. coli) and incubated at $30^{\circ} \mathrm{C}$ for $24 \mathrm{~h}$. The growth on the agar slants was scraped, using $5 \mathrm{ml}$ sterilized distilled water, then transferred to a flask containing $100 \mathrm{ml}$ of Nutrient broth medium (Oxoid, UK), which has the following composition (1.0 g Lab-Lemco powder,5.0 g sodium chloride, $5.0 \mathrm{~g}$ peptone, 2.0 g yeast extract @ pH 7.4 \pm 0.2 and $25^{\circ} \mathrm{C}$ ) and incubated for $24 \mathrm{~h}$ on a rotary shaker operating at $150 \mathrm{rpm}$ at $30^{\circ} \mathrm{C}$. One $\mathrm{ml}\left(1 \times 10^{8} \mathrm{cfu} \mathrm{ml}^{-1}\right)$ of 24 hours old liquid cultures of bacterial strains was transferred to each flask containing $100 \mathrm{ml}$ of the above medium, which containing $5 \mathrm{mgL}$ ${ }^{1}$ of titanium (Ti), vanadium (V), cobalt (Co), nickel (Ni), selenium (Se), molybdenum (Mo)

Env. Biodiv. Soil Security Vol. 5 (2021) and boron (B), then the flasks were incubated on a rotary shaker operating at $150 \mathrm{rpm}$ at $30^{\circ} \mathrm{C}$ for $48 \mathrm{~h}$. The experiment was conducted in triplicate. All trace elements were spiked in their mineral forms $\left(\mathrm{TiO}_{2}, \mathrm{~V}_{2} \mathrm{O}_{5}, \mathrm{Co}_{3} \mathrm{O}_{4}, \mathrm{NiO}, \mathrm{SeO}_{2}\right.$, $\mathrm{MoO}_{3}$ and $\mathrm{B}_{2} \mathrm{O}_{3}$ for Ti, $\mathrm{V}, \mathrm{Co}, \mathrm{Ni}, \mathrm{Se}, \mathrm{Mo}$, and $\mathrm{B}$, respectively) at the concentration of $5.0 \mathrm{mg}$ $\mathrm{L}^{-1}$. The bacterial growth in the culture media was measured as optical density at wave length of 600 $\mathrm{nm}$. The contents of the flasks were centrifuged at $4000 \mathrm{rpm}$ for $20 \mathrm{~min}$ at $4^{\circ} \mathrm{C}$ to investigate the surface elemental distribution of elements onto the solid phase. Thereafter, the liquid phase was acid digested using aqua regia solution $\left(\mathrm{HCl}-\mathrm{HNO}_{3}\right.$ mixture, 3:1 v/v) in a microwave digestion unit (Milestone MLS 1200 Mega) for elemental determination of by ICP-OES. The total concentrations of nitrogen $(\mathrm{N})$ and carbon (C) were measured using dry combustion method by a Thermo Scientific Flash 2000 elemental analyzer. Concentrations of inorganic elements were determined using an Inductivity Coupled Plasma-Optical Emission Specrtoscopy (Thermo Scientific TMiCAPTM 7000 Plus Series ICPOES). The surface elemental analysis was performed using an energy dispersive X-ray spectroscopy or EDS (Oxford X-Max 20).

All laboratory experimentations were carried out under constant temperature $\left(25 \pm 0.5{ }^{\circ} \mathrm{C}\right)$ with appropriate replications, controls and blanks. Chemical reagents (LobaChemie Pvt. Ltd)were used without additional purification and the chemical solutions were prepared using deionized water (18.2 MD) (Nanopure water, Barnstead). Organic elements determination was optimized using aspartic acid standard and inorganic elementsdetermination was optimized verified by standard calibration solutions

\section{Results and Discussion}

\section{The history of atom and its evolution}

History of Atomic Theory started from 400-350 BC Greek Philosophers' Views when Democritus 400 BC states "The matter consists of the small particles known as atoms; these atoms cannot be further divided" (Albanese and Vicentini, 1997). Whereas, Aristotle 350 BC states "Matter is made of earth, fire, water and air. It can always be broken down into smaller parts" (Dekker 2016). Dalton's Modern Atomic Theory hypothesized in 1803 that (i) matter consists of indivisible and indestructible atoms, (ii) element atoms are identical, (iii) atoms of the various elements have varying chemical characteristics 
and weights; atoms of of the various elements combine to form compounds, and (v) atoms can not be produced or damaged, which later proved to be a wrong theory (De Laeter et al. 2003). In the late nineteenth and early twentieth century (1897-1940), the electron has been discovered by J. J. Thomson in 1904 (Fig. 2) by deflecting the stream of rays from the negatively charged plate and towards the positively charged plate. He stated that these rays were electrons carrying negative charges, and then assumed his atomic model of "Plum Pudding". He believed that the electrons were uniformly mixed between an atom's positive charges as theplums were mixed in the plum pudding (Retsky, 2003).

The scientific groups (Protons \& discovered,
Ernest Rutherford and Ernest Marsden \& Hans Geiger) (Fig. 2) showed the wrong hypothesis of Thomson's Plum Pudding model in 1911. Protons and nucleus were discovered through shooting positively charged alpha particles on a thin sheet of gold (Romer, 1997).

The majority of the particles were transferred, but some were deviated backwards and sideways. Rutherford considered the bulk of the atom is empty space and that the protons are positive particles, situated in the middle of the atom in a dense nucleus (Lenshof and Laurell, 2010). Niels Bohr developed his model (Bohr Model of the Atom), which revealed the electrons surrounding the nucleus in separate levels of energy, much as the planets orbit the sun in 1913 .

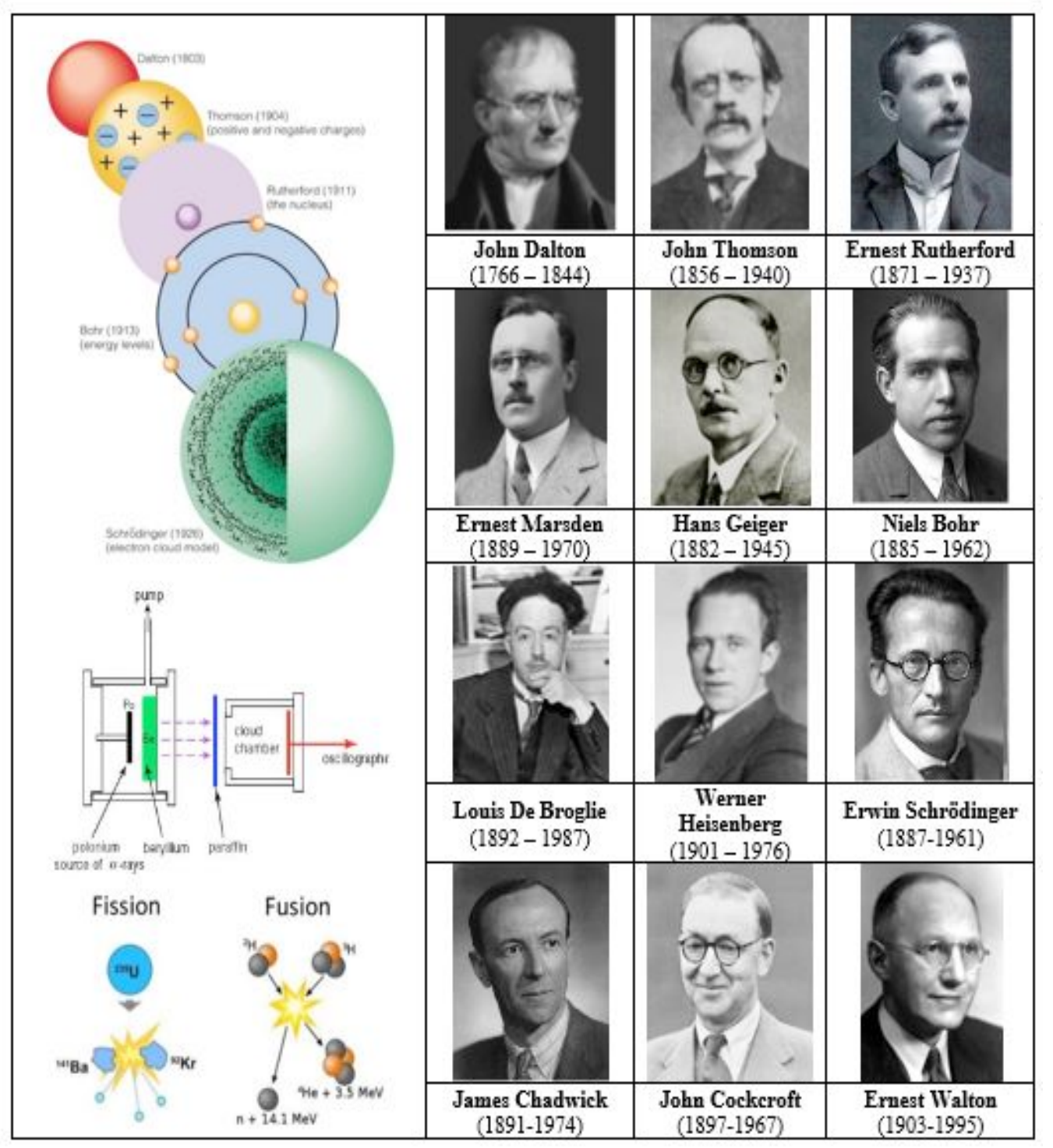

Fig. 2. The most famous scientists in the field of evolution of the atom history. 
This model describes the spectrum of hydrogen atomic emissions, but has not clarified the spectra of emissions of other elements (Kelly and Palumbo, 1973; Tanner et al. 2000). Thereafter, between 1924-1928 the Quantum Model of the Atom was proposed by Erwin Schroedinger, Werner Heisenberg and Louis De-Broglie; separately, and they assumed that electrons had wave-like properties and circulated around the nucleus inside complicated regions called orbitals. This theory remains valid nearly 100 years later (Ireson 2000 and Kirilyuk, 2001).

James Chadwick proposed that the core of an atom contained an uncharged particle, which called the neutron in mid-1932. He also reported that there were neutral particles present in the nucleus with approximately the same mass called protons. This discover proved the wrong hypothesis of Dalton's $2^{\text {nd }}$ Law that all atoms are identical to the same element. In view of this, he also hypothesized that isotopes of an element are atoms with different numbers of neutrons but the same number of protons. He shot a thin beryllium foil with alpha particles emitted by polonium, and he discovered that the beryllium emitted secondary radiation that resented neither an electric field nor a magnetic field (Horrobin, 1971; Schmidt et al., 2003; Khazan, 2007). In the same year (1932), John Cockcroft and Ernest Walton shot atoms of lithium with protons and and divided them into two atoms of helium. This finding opposed Dalton's Fifth Law that atoms can not be split, destroyed or created (Matthews, 2014).

\section{Bacterial growth and bio-availability of trace elements}

As illustrated in Table 1, although the obtained results showed that the conversion of high phosphorus amounts, cobalt not only supports in avoiding the conversion of phosphate but it also increased its rate, which positively increased the growth of bacteria. In addition, Ti, Se and B elements showed elevated levels. However, Ni, V, Mo showed significant effect on the conversion of phosphorus into other elements, which might be beneficial to the bacterial growth such as Mo or hazard elements such as $\mathrm{Ni}, \mathrm{Se}$ or $\mathrm{B}$ as the bacterial levels showed a noticeable reduction.

The bacterial cell can convert some elements into others according to the cell actual requirements. As illustrated in Table 1, it could be recognized that some elements concentration has been decreased (e.g Ti and B). Other showed noticeable increase in their concentrations (e.g Se, $\mathrm{V}$ and $\mathrm{Ni}$ ) and some elements were vanished and were not detected during ICP-OES determination

Env. Biodiv. Soil Security Vol. 5 (2021) (e.g. Ag, B and Cd). This noticeable alteration in elements concentration is occurred precisely according to the cell needs. Moreover, it could be recognized that the trace elements play key-roles as catalytic agents. In this regards, it has been shown that the addition of $\mathrm{V}, \mathrm{Co}, \mathrm{Ni}, \mathrm{Se}, \mathrm{Mo}$, and $\mathrm{B}$ to $\mathrm{B}$. amyloliquefaciens culture medium enhanced $\mathrm{Bi}$ bio-synthesis. It is expected that the final concentrations of elements will not be altered compared to the initial concentration as the experiment was carried out in a closed system according to the law of energy conservation. These results may be attributed to the occurrence of nuclear adhesion, and the element will not be detectable by ICP-OES. Also, it is expected that the change of ambient conditions of the cell i.e; temperature, aeration, light and other factors support in the synthesis of new elements and this hypothesis needs further research.

\section{EDS spectra mapping in the solid phase of the media}

A representative image of trace elements with EDS analysis from B. amyloliquefaciens. Spectra on the left and right represent EDS spectra on and off the granule, respectively. The elemental distribution on the outersphere surfaces are illustrated in Fig. 3. In general, $\mathrm{O}, \mathrm{Na}$ and $\mathrm{Mg}$ were the most dominant elements in most cases. Carbon was the dominant element when $B$. amyloliquefaciensspiked with $\mathrm{Ti}$ and Ni (Fig. 4). Substantial alterations in elements concentration were recorded taking into consideration the data of EDS. Some elements (e.g., Bi) vanished completely in both media (Fig. 5), which might be considered as a raw element for generating other elements. On the other hand, some elements (e.g., $\mathrm{Ca}$ and $\mathrm{Mg}$ ) showed multiplications with both media. Other elements (e.g., $\mathrm{Al}, \mathrm{Hg}$ and $\mathrm{Cu}$ ) showed noticeable reductions. Meanwhile, it is clearly noticeable that $\mathrm{Cd}$ concentration was constant in all cases $\left(0.05 \mu \mathrm{g} \mathrm{g}^{-1}\right)$. It is noticed that there is substantial alterations in elements synthesis and its concentration when trace elements were added as catalysts.

It is expected that each organism has a pathway for elements conversion according to its requirement, and cells differ in its conversion ratios. This finding supports our hypothesis that the live cell can synthesis its required elements through nuclear fission into two nucleuses, which could not be equal. Or through merging of two nucleuses through adhesion from one element or different elements according to the exact needs (Fig. 6). If we imagine that the living cell in the organisms is looks like the atom in the elements, the potential adhesion between two living cells or nuclei and merging of cytoplasm surrounded by electrons. 
TABLE 1. Changing rate in concentration of elements $\left(\mathrm{mg} \mathrm{L}^{-1}\right)$ in bacterial growth medium and the catalytic role of trace elements (the initial concentration of elements was $5 \mathrm{mg} \mathrm{L}^{-1}$ )

\begin{tabular}{|c|c|c|c|c|c|c|c|c|c|}
\hline Elements & $\begin{array}{l}\text { Medium } \\
\text { (M) }\end{array}$ & $\mathbf{M}+\mathbf{B s}$ & $\begin{array}{c}\mathbf{M}+\mathbf{B s} \\
+\mathbf{T i}\end{array}$ & $\begin{array}{c}\mathbf{M}+\mathbf{B s} \\
+\mathbf{V}\end{array}$ & $\begin{array}{l}\mathrm{M}+\mathrm{Bs} \\
+\mathbf{C o}\end{array}$ & $\begin{array}{c}\mathbf{M}+\mathbf{B s} \\
\quad+\mathbf{N i}\end{array}$ & $\begin{array}{c}\mathbf{M}+\mathbf{B s} \\
+\mathbf{S e}\end{array}$ & $\begin{array}{c}\text { M + Bs } \\
+ \text { Mo }\end{array}$ & $\begin{array}{l}\mathbf{M}+\mathbf{B s} \\
\quad+\mathbf{B}\end{array}$ \\
\hline Se & -- & 0.41 & 0.63 & 0.152 & 0.664 & 0.184 & 3.727 & -0.032 & 0.232 \\
\hline $\mathbf{V}$ & -- & -- & -- & 0.90 & -- & -- & -- & -- & -- \\
\hline Al & 21.78 & 17.56 & 15.53 & 16.52 & 16.26 & 20.48 & 18.44 & 15.68 & 16.42 \\
\hline $\mathbf{T i}$ & 451.43 & 225.0 & 402.69 & 191.2 & 326.2 & 264.8 & 343.3 & 489.0 & 329.0 \\
\hline $\mathbf{B i}$ & -- & -- & -- & 0.567 & 0.736 & 1.145 & 0.044 & 1.395 & 0.173 \\
\hline $\mathbf{H g}$ & 1.791 & 0.873 & 0.682 & 0.509 & 0.366 & 0.253 & 0.172 & 0.189 & 0.152 \\
\hline Ag & 0.497 & 0.189 & -- & -- & -- & 0.138 & 0.055 & -- & -- \\
\hline B & 0.843 & 0.192 & 0.314 & 0.133 & 0.089 & 0.033 & -- & 0.023 & 0.708 \\
\hline $\mathbf{B a}$ & 1.220 & 1.134 & 0.533 & 0.533 & 0.357 & 0.3 & 0.285 & 0.636 & 0.309 \\
\hline $\mathrm{Ca}$ & 435.9 & 363.6 & 174.8 & 325.1 & 180.0 & 175.3 & 135.6 & 151.6 & 168.1 \\
\hline Cd & 0.031 & -- & 0 & 0.012 & 0.007 & -0.01 & 0.009 & -- & 0.032 \\
\hline Co & 0.03 & 0.039 & 0.072 & 0.057 & 1.909 & 0.123 & 0.049 & 0.056 & -- \\
\hline $\mathrm{Cr}$ & 3.113 & 3.34 & 2.399 & 2.372 & 2.197 & 3.038 & 3.346 & 3.015 & 2.33 \\
\hline $\mathrm{Cu}$ & 1.742 & 1.285 & 0.663 & 1.138 & 1.587 & 0.372 & 0.752 & 1.104 & 1.355 \\
\hline $\mathrm{Fe}$ & 17.47 & 13.71 & 12.66 & 12.85 & 13.37 & 16.42 & 14.70 & 13.42 & 13.48 \\
\hline Ga & -- & 1.146 & 0.613 & -- & -- & 3.321 & -- & -- & -- \\
\hline In & -0.41 & 1.183 & 3.543 & 2.632 & -0.434 & -0.72 & -0.552 & 1.688 & 1.34 \\
\hline $\mathbf{K}$ & 183.152 & 188.5 & 147.3 & 161.5 & 154.8 & 148.9 & 164.3 & 154.7 & 159.2 \\
\hline $\mathbf{L i}$ & 0.09 & -- & -- & 0.079 & -- & -- & -- & -- & 0.113 \\
\hline Mg & 29.702 & 26.51 & 28.22 & 32.62 & 27.53 & 24.91 & 24.78 & 30.92 & 26.26 \\
\hline Mn & 0.569 & 0.453 & 0.353 & 0.438 & 0.425 & 0.45 & 0.375 & 0.352 & 0.41 \\
\hline $\mathbf{N i}$ & 1.989 & 1.195 & 1.456 & 1.396 & 1.435 & 3.019 & 1.896 & 1.602 & 1.241 \\
\hline $\mathbf{P b}$ & 1.885 & 1.872 & 2.587 & 0.726 & 1.781 & 1.486 & 0.404 & 0.135 & 1.639 \\
\hline $\mathrm{Sr}$ & 0.684 & 0.63 & 0.807 & 0.914 & 0.817 & 0.697 & 0.698 & 0.823 & 0.731 \\
\hline $\mathrm{Zn}$ & 3.119 & 2.423 & 2.403 & 4.798 & 2.487 & 2.506 & 2.124 & 2.102 & 2.217 \\
\hline $\mathbf{S}$ & 276.992 & 283.6 & 278.9 & 200.8 & 356.4 & 185.2 & 204.9 & 185.6 & 263.3 \\
\hline Mo & 0.428 & 0.464 & 0.193 & 0.413 & 0.49 & 0.591 & 0.508 & 3.251 & 0.189 \\
\hline
\end{tabular}

Abbreviations: Calcium (Ca), Titanium (Ti), Potassium (K), Magnesium (Mg), Aluminium (Al), Iron (Fe), Bismuth (Bi), Mercury (Hg), Silver (Ag), Boron (B), Barium (Ba), Selenium (Se), Cadmium (Cd), Cobalt (Co), Chromium (Cr), Copper (Cu), Gallium (Ga), Lithium (Li), Manganese (Mn), Nickel (Ni), Lead (Pb), Strontium (Sr), Zinc (Zn), Sulfur (S) and Molybdenum (Mo). 


\section{A. Bacillus}

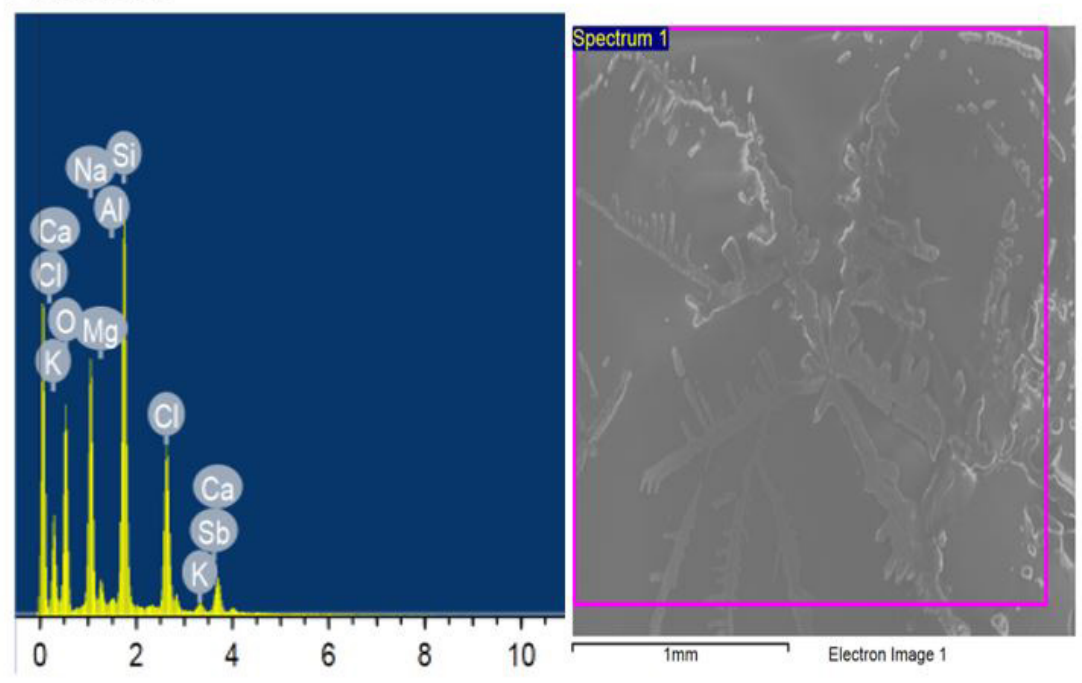

\section{B. Bacillus $+\mathrm{Ti}$}
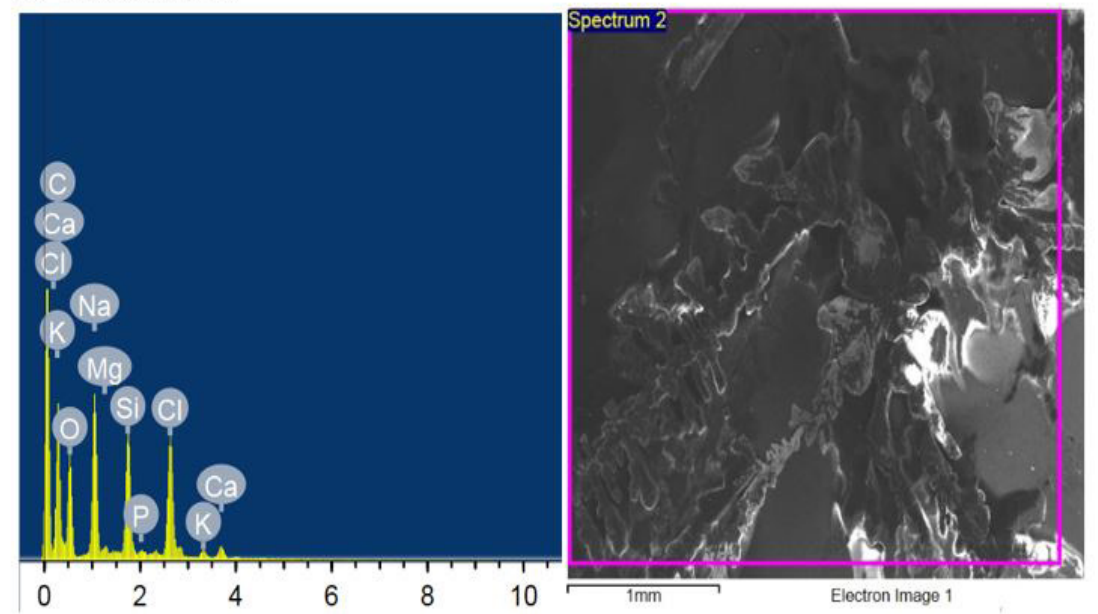

Elem... Weight\% Atomic\%

$\begin{array}{lll}\text { CK } & 56.25 & 67.30\end{array}$

$\begin{array}{lll}\text { OK } & 26.20 & 23.53\end{array}$

$\begin{array}{lll}\mathrm{NaK} & 7.43 & 4.65\end{array}$

$\begin{array}{lll}\text { MgK } & 0.32 & 0.19\end{array}$

$\begin{array}{lll}\text { SiK } & 3.75 & 1.92\end{array}$

$\begin{array}{lll}\text { PK } & 0.17 & 0.08\end{array}$

$\begin{array}{lll}\text { ClK } & 4.85 & 1.97\end{array}$

$\begin{array}{lll}\text { KK } & 0.40 & 0.15\end{array}$

$\begin{array}{lll}\text { CaK } & 0.62 & 0.22\end{array}$

Totals $\quad 100.00$

\section{Bacillus $+\mathrm{V}$}
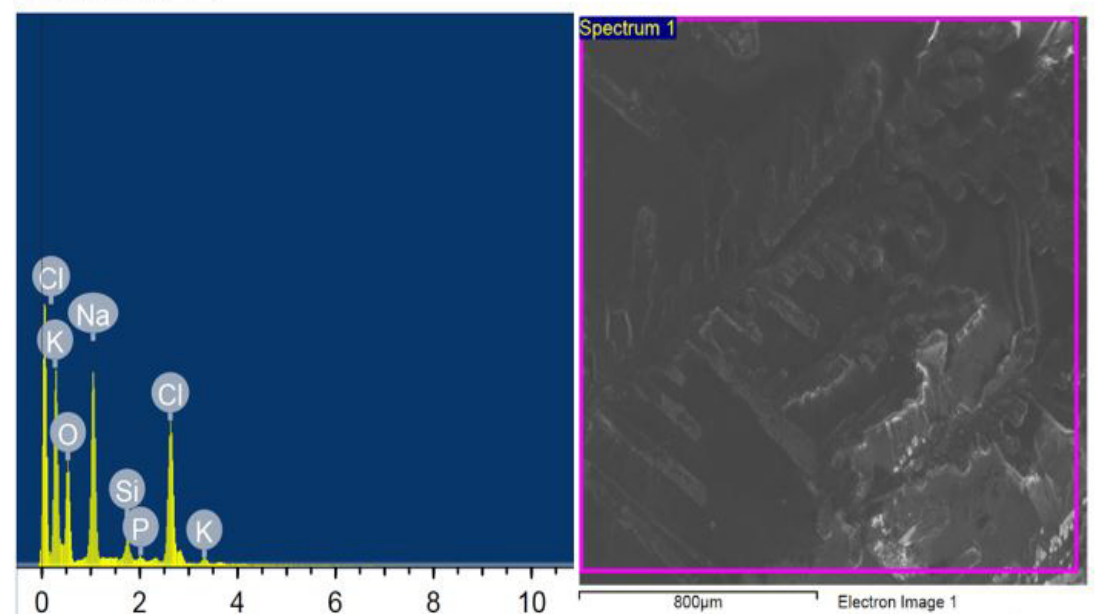

Elem... Weight\% Atomic\%

OK $\quad 46.48 \quad 59.46$ $\begin{array}{lll}\mathrm{NaK} & 29.51 \quad 26.28\end{array}$ $\begin{array}{lll}\text { SiK } & 2.67 \quad 1.94\end{array}$

$\begin{array}{lll}\text { PK } & 0.70 & 0.46\end{array}$ $\begin{array}{lll}\text { CIK } & 19.45 & 11.23\end{array}$ $\begin{array}{lll}K K & 1.20 & 0.63\end{array}$

Totals $\quad 100.00$

Fig. 3. EDS analysis of A. Bacillus, B. Bacillus + Ti, C. Bacillus $+V$, D. Bacillus + Co, E. Bacillus $+N i$, F. Bacillus $+S e$, G. Bacillus + Mo, H. Bacillus + B. 


\section{Bacillus +Co}

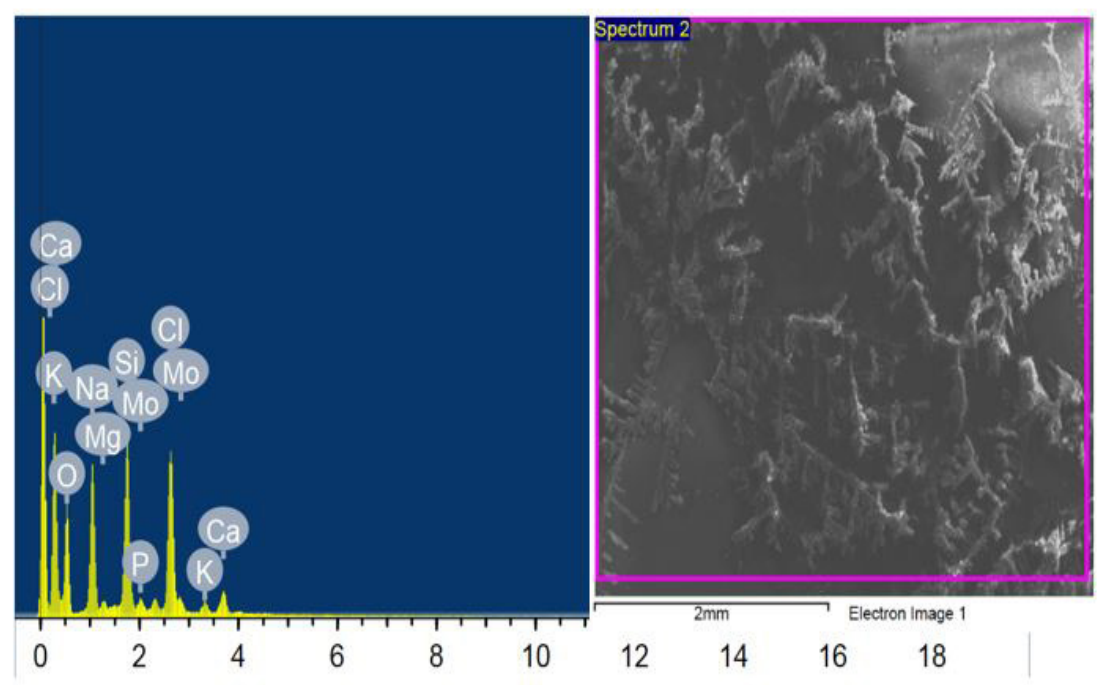

Elem... Weight\% Atomic\%

$\begin{array}{lll}\text { OK } & 42.45 \quad 57.98\end{array}$

$\begin{array}{lll}\mathrm{NaK} & 16.76 \quad 15.93\end{array}$

$\begin{array}{lll}M g K & 1.04 & 0.94\end{array}$

$\begin{array}{lll}\text { SiK } & 13.53 & 10.53\end{array}$

$\begin{array}{lll}\text { PK } & 1.10 & 0.78\end{array}$

$\begin{array}{lll}\text { CIK } & 17.34 & 10.69\end{array}$

$\begin{array}{lll}\text { KK } & 1.47 & 0.82\end{array}$

$\begin{array}{lll}\text { CaK } & 2.79 & 1.52\end{array}$

MoL $\quad 3.50 \quad 0.80$

\section{E. Bacillus $+\mathrm{Ni}$}
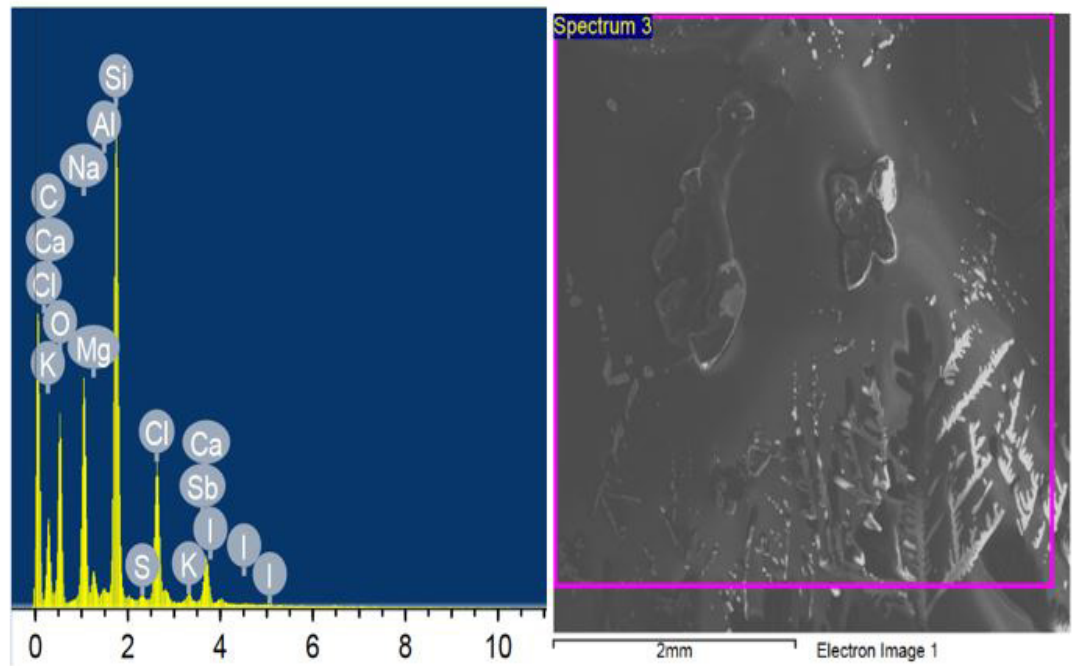

Elem... Weight\% Atomic\%

$\begin{array}{lll}\text { CK } & 31.03 \quad 43.51\end{array}$

OK $\quad 34.58 \quad 36.40$

NaK $\quad 9.51 \quad 6.97$

$\begin{array}{lll}M g K & 0.99 & 0.68\end{array}$

$\begin{array}{lll}\text { AlK } & 0.26 & 0.16\end{array}$

SiK $\quad 13.89 \quad 8.33$

$\begin{array}{lll}\text { SK } & 0.24 & 0.12\end{array}$

$\begin{array}{lll}\text { ClK } & 5.25 & 2.49\end{array}$

$\begin{array}{lll}\text { KK } & 0.31 & 0.13\end{array}$

$\begin{array}{lll}\text { CaK } & 2.32 & 0.97\end{array}$

$\begin{array}{lll}\mathrm{SbL} & 1.15 \quad 0.16\end{array}$

$\begin{array}{lll}\text { IL } & 0.48 & 0.06\end{array}$

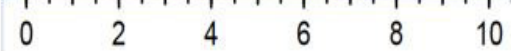

Totals $\quad 100.00$

\section{F. Bacillus +Se}
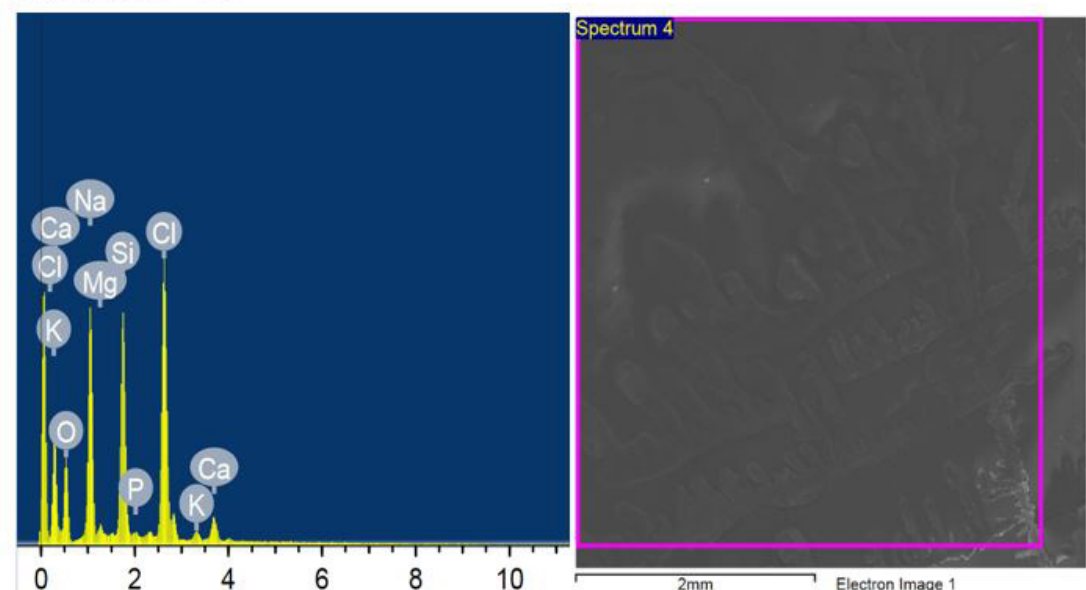

Elem... Weight $\%$ Atomic $\%$

$\begin{array}{lrr}\text { O K } & 32.39 & 46.27 \\ \text { Na K } & 21.09 & 20.97 \\ \text { Mg K } & 1.11 & 1.04 \\ \text { Si K } & 15.77 & 12.83 \\ \text { P K } & 0.52 & 0.39 \\ \text { Cl K } & 25.40 & 16.37 \\ \text { K K } & 1.08 & 0.63 \\ \text { CaK } & 2.64 & 1.51 \\ & & \\ \text { Totals } & 100.00 & \end{array}$

Cont.

Fig. 3. EDS analysis of A. Bacillus, B. Bacillus + Ti, C. Bacillus + V, D. Bacillus + Co, E. Bacillus + Ni, F. Bacillus + Se, G. Bacillus +Mo, H. Bacillus + B. 


\section{G. Bacillus +Mo}

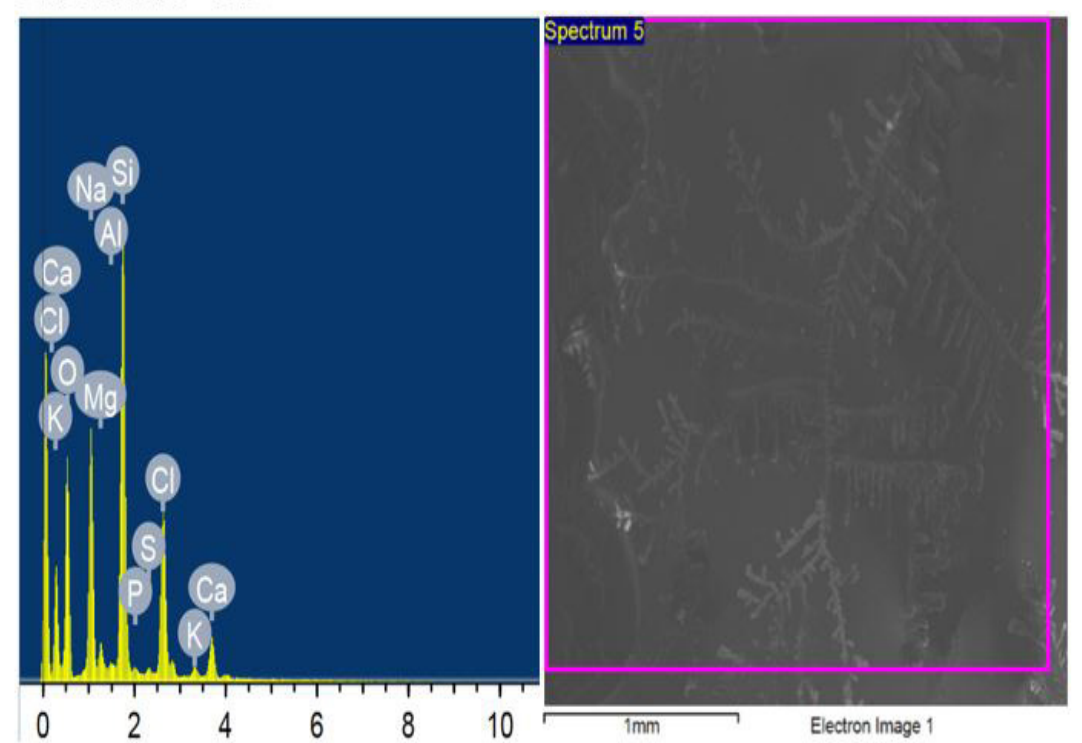

Elem... Weight \% Atomic\%

$\begin{array}{lll}\text { OK } & 44.83 & 58.60\end{array}$

$\begin{array}{lll}\mathrm{NaK} & 16.30 & 14.83\end{array}$

$\begin{array}{lll}\text { MgK } & 1.71 \quad 1.47\end{array}$

$\begin{array}{lll}\text { AlK } & 0.37 & 0.29\end{array}$

SiK $\quad 21.27 \quad 15.84$

$\begin{array}{lll}\text { PK } & 0.44 & 0.30\end{array}$

$\begin{array}{lll}\text { SK } & 0.49 & 0.32\end{array}$

$\begin{array}{lll}\text { ClK } & 10.88 & 6.42\end{array}$

$\begin{array}{lll}\text { KK } & 0.76 & 0.41\end{array}$

$\begin{array}{lll}\text { CaK } & 2.95 & 1.54\end{array}$

Totals $\quad 100.00$

\section{H. Bacillus +B}
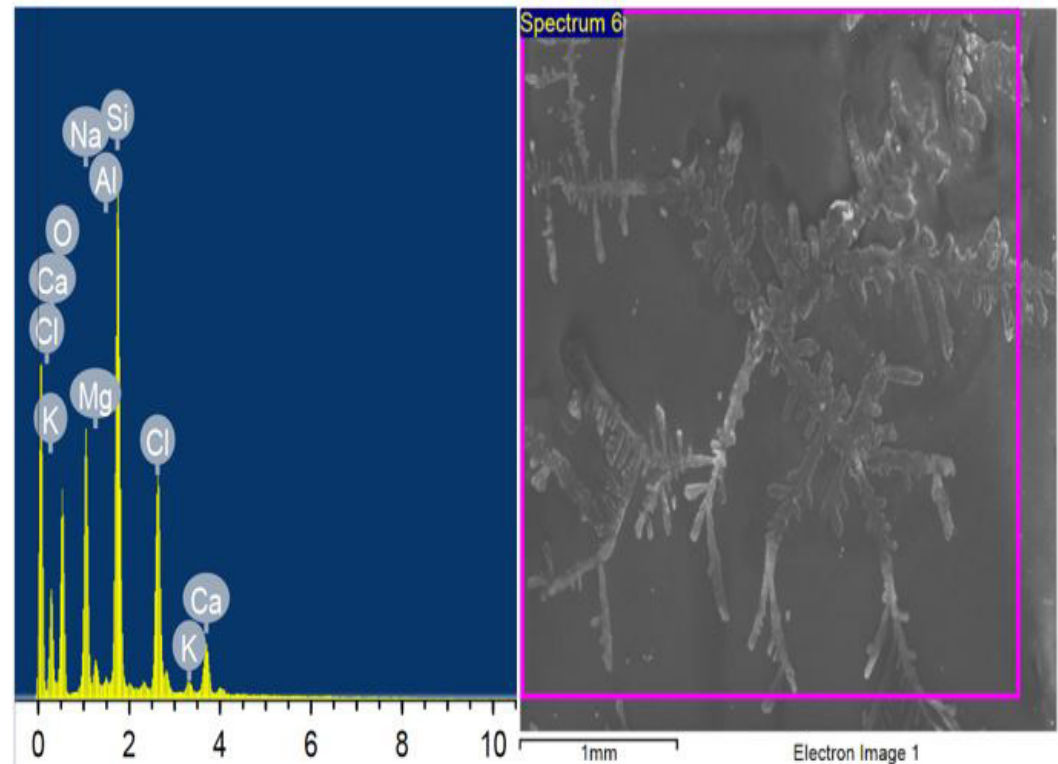

Elem... Weight\% Atomic\%

$\begin{array}{lll}\text { OK } & 42.05 \quad 56.10\end{array}$

$\begin{array}{lll}\mathrm{NaK} & 15.98 \quad 14.83\end{array}$

$\begin{array}{lll}\text { MgK } & 1.65 \quad 1.45\end{array}$

$\begin{array}{lll}\text { AlK } & 0.38 & 0.30\end{array}$

SiK $\quad 22.50 \quad 17.10$

$\begin{array}{lll}\text { ClK } & 13.16 \quad 7.92\end{array}$

$\begin{array}{lll}K K & 0.84 & 0.46\end{array}$

$\begin{array}{lll}\text { CaK } & 3.44 & 1.83\end{array}$

Totals $\quad 100.00$

Cont.

Fig. 3. EDS analysis of A. Bacillus, B. Bacillus +Ti, C. Bacillus +V, D. Bacillus +Co, E. Bacillus +Ni, F. Bacillus +Se, G. Bacillus + Mo, H. Bacillus $+B$. 


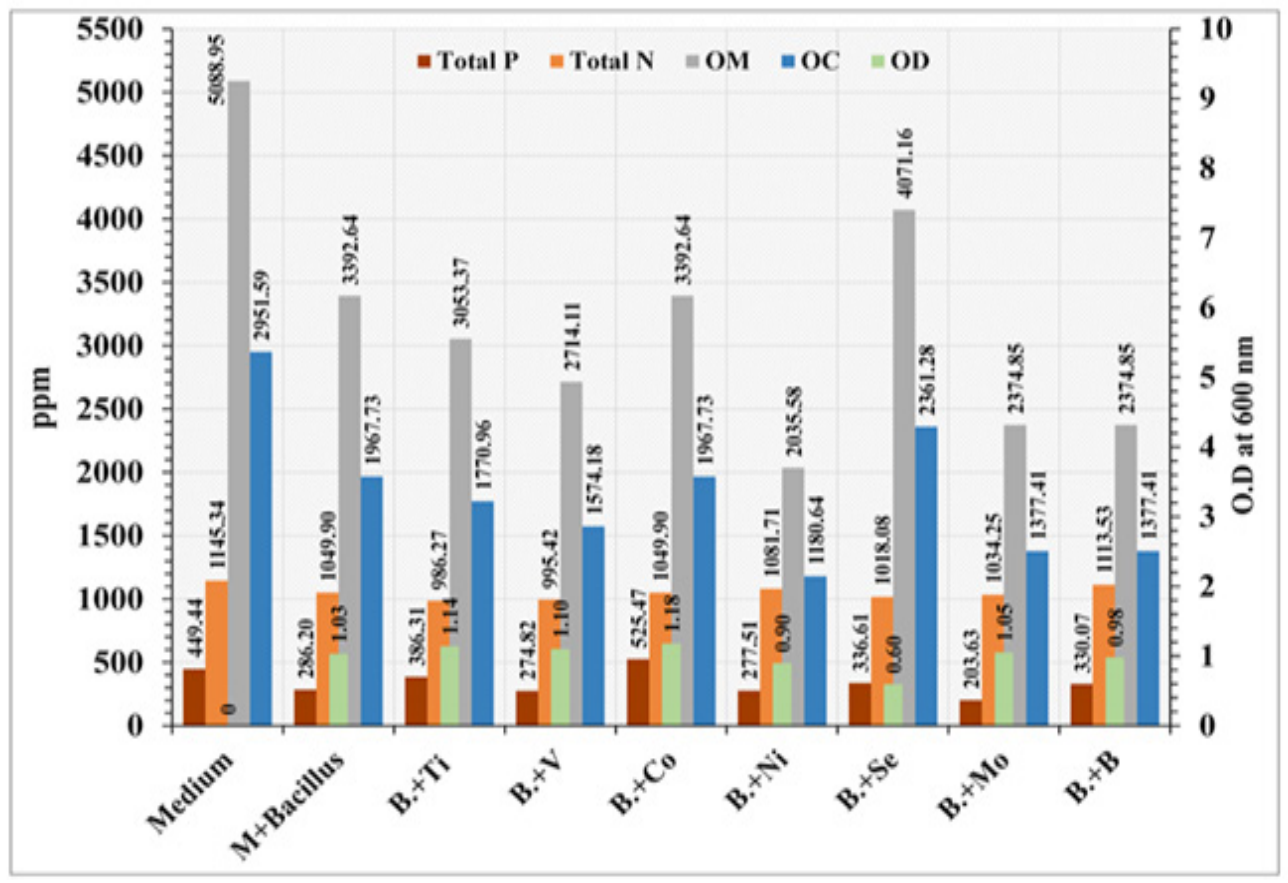

Fig. 4. Alterations in bacterial growth in the presence or absence of trace elements and the subsequent alterations in phosphorus, total nitrogen and organic matter concentrations in bacterial growth media. B. Bacillus amyloliquefaciens, Titanium (Ti), Vanadium (V), Cobalt (Co), Nickel (Ni), Selenium (Se), Molybdenum (Mo) and Boron (B)

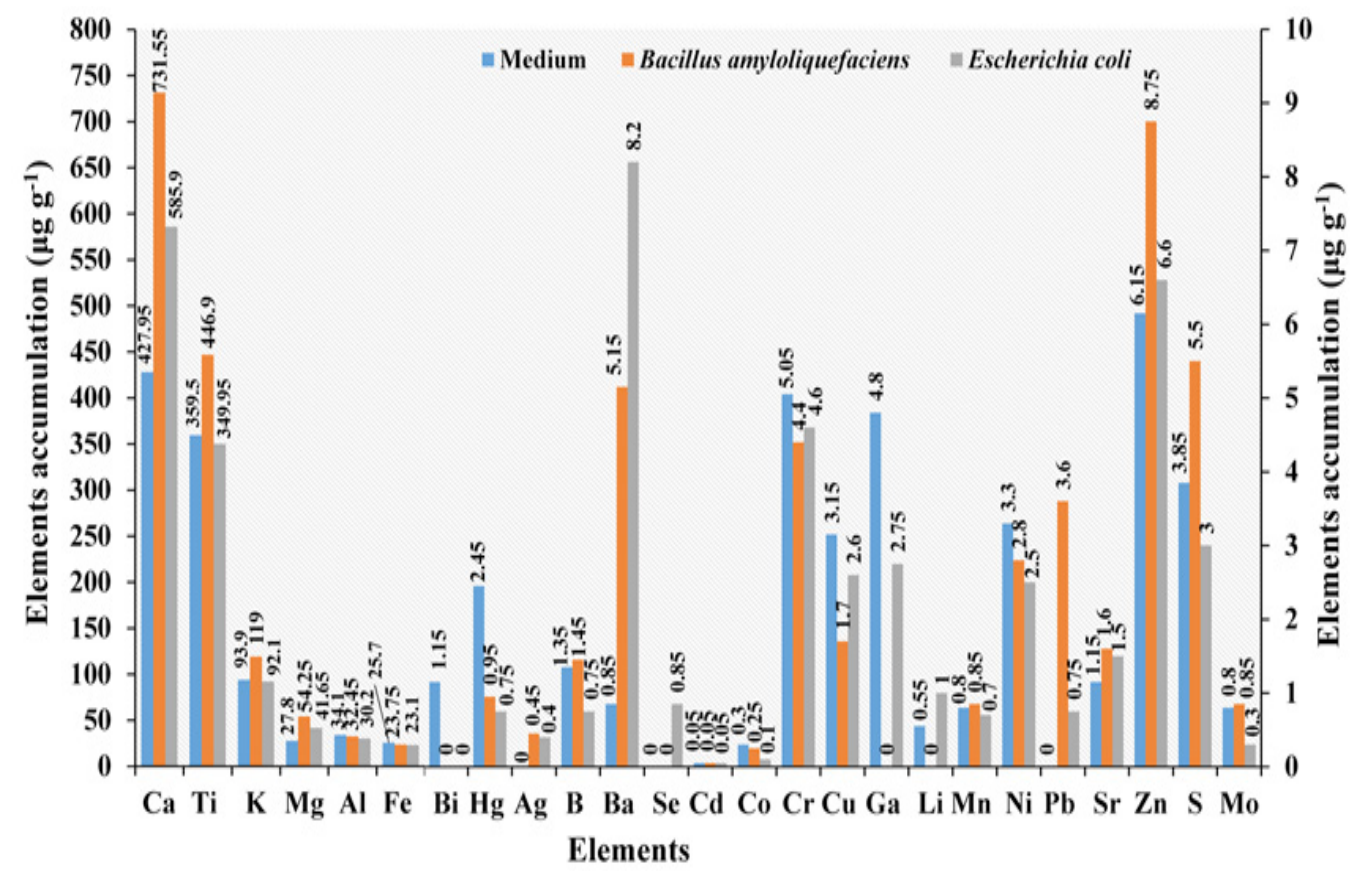

Fig. 5. Alterations in elements accumulation $\left(\mu \mathrm{g} \mathrm{g}^{-1}\right)$ in Bacillus amyloliquefaciens and Escherichia colimedium. Calcium (Ca), Titanium (Ti), Potassium (K), Magnesium (Mg), Aluminium (Al), Iron (Fe), Bismuth (Bi), Mercury (Hg), Silver (Ag), Boron (B), Barium (Ba), Selenium (Se), Cadmium (Cd), Cobalt (Co), Chromium (Cr), Copper (Cu), Gallium (Ga), Lithium (Li), Manganese (Mn), Nickel (Ni), Lead (Pb), Strontium (Sr), Zinc (Zn), Sulfur (S) and Molybdenum (Mo) 

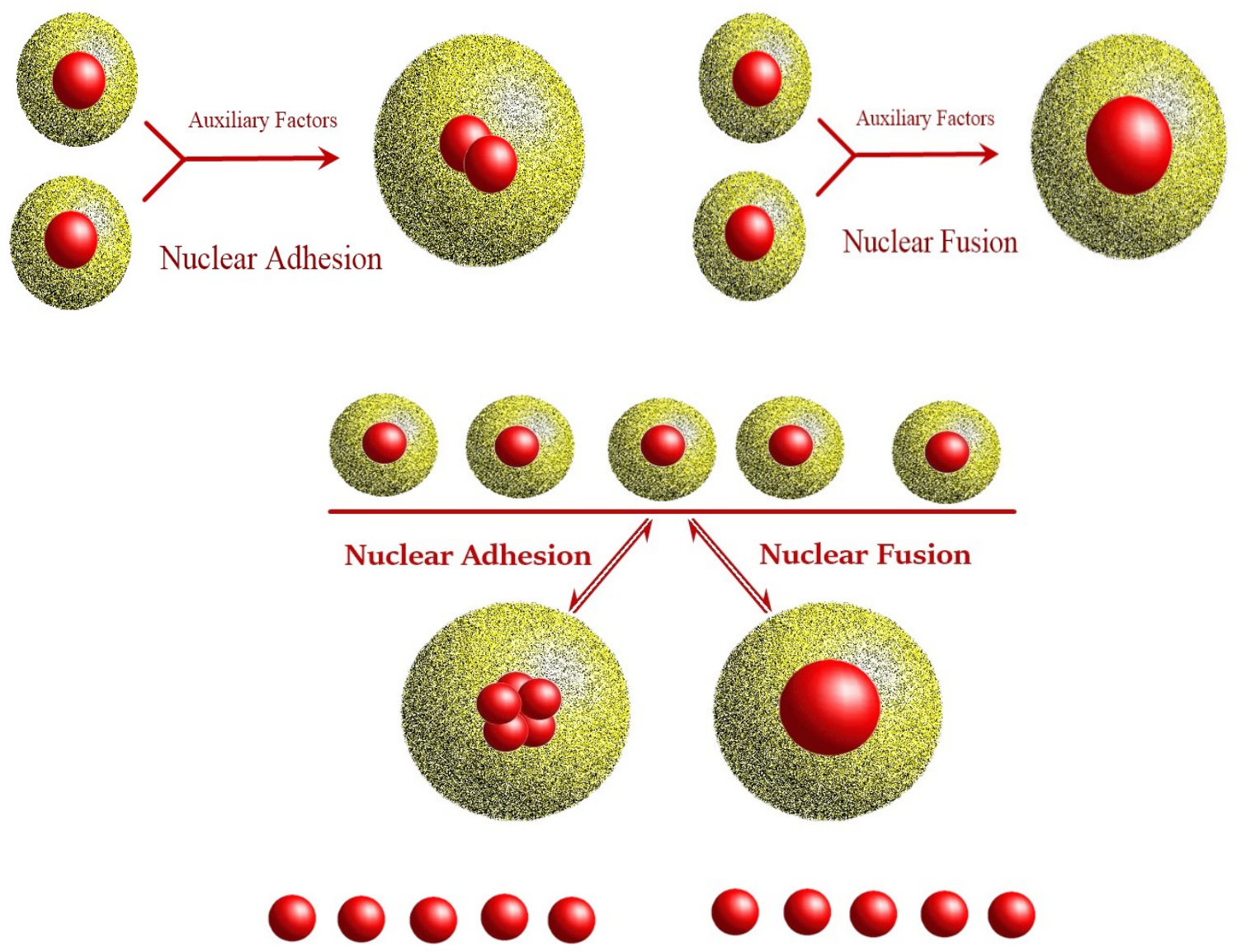

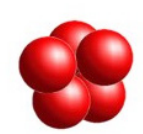

Nuclear Adhesion

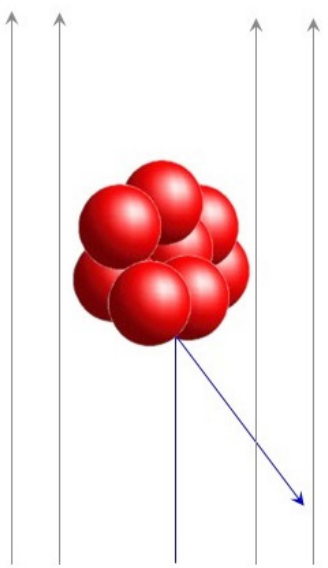

Nuclear Fusion

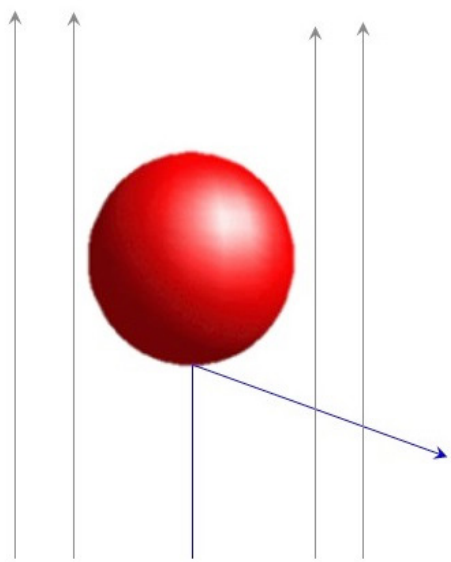

Fig. 6. A hypothesis for the elemental determination in case of original nuclei or that originated from nuclear adhesion or nuclear fusion

Env. Biodiv. Soil Security Vol. 5 (2021) 
In case of nuclear adhesion process, it is noted that the nuclei of two or more atoms adhere to the same structure with each other without merging. Then, electronic clouds merging around it to envelop them in one electronic cloud. In this case, the new generated element will be different than the original ones. Therefore, it will not be detected during analysis and the concentration of the original element will be reduced. This element can be called the compound element or the complicated element, which has the same number of protons and neutrons, a mega nucleus generated from the adhesion of two or more nuclei and electrons orbiting naturally. Although this new element will be partially similar to the original one, it is completely different in its characters and effects on the live cells. Based on this theory, the live cell (microbial, plant and animal cells) can synthesis its elemental needs through nuclear adhesion in a similar way to the nuclear reactor. As mentioned before, these elements cannot be determined during elemental analysis. This theory can interpret the potentiality of organisms to complete its life cycle with limited macro- and micro-elements (not more than 16 elements) and can synthesize its elemental needs through nuclear adhesion by the nuclear reactor inside the live cells (cell reactor).

To approximate the idea of forming adherent nuclei in atoms can be described as it happens in homo-karyocyte. Whereas, a protoplast is a plant, bacterial or fungal cell without completely cell wall. The protoplast is an excellent tool for the synthesis of novel combination of genes and it is an important component of the overall process needed to manipulate the genes of plants. In plant for example, to produce a new somatic hybridisation, two distinct genetically derived protoplasts from distinct somatic cells are fused. The fusion of two cytoplasms results in cytoplasm coalescence. Even after cytoplasm fusion the nuclei of two protoplasts may or may not fuse together. The cells are known as hybrid, once nuclei are fused. Whereas only cytoplasm fuse and genetic information is lost from one of the two nuclei is called cybrid (cytoplasmic hybrid) (Miller et al., 1971; Motoyoshi, 1971; Withers and Cocking, 1972; Woodcock, 1973; Brar et al., 1979). Maybe the same behaviors occur in all living cells for generation of new elements by either nuclear fusion or forming adherent nuclei surrounded by electrons.

Additionally, we can understand the behavior of an element in its different states as the element in its ordinary state is different than its nano or pico states. Nano or pico states can be generated through the live cells where the element can be transformed from a toxic element to a beneficial element. Consequently, it can be stated that the element in its ordinary form is different than its other states, which generated by nuclear fusion, nuclear adhesion (Fig. 6) and nuclear fission (Fig. 7) although the molecular and atomic weight are similar. Certainly, the cell is able to differentiate among these states and can use the element in its suitable form/state. We can also interpret the beneficial effect of bio-fertilization by fungi and algae as the bio-generated derivatives are suitable to the needs of plant and animal cells.

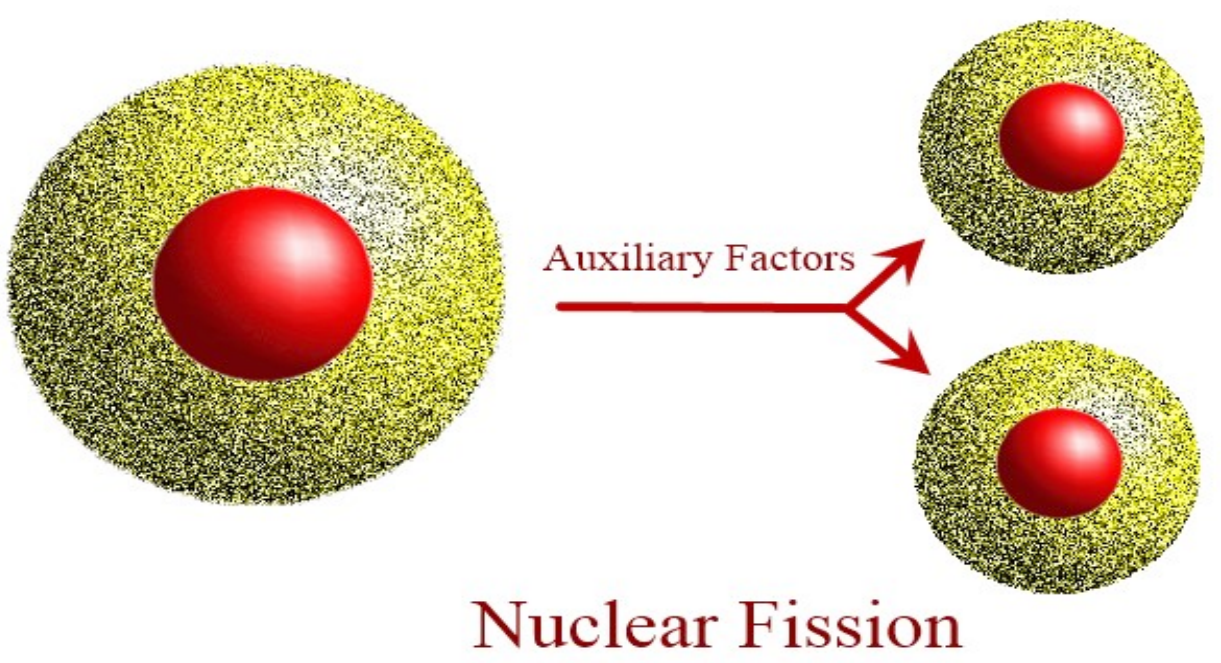

Fig. 7. Illustration of the nuclear fission 
Characteristics of these elements, which generated by the proposed theories, are beneficial to plants or animals due to their high availability/ accessibility into the live cells. This is why the most of bio-products are more effective relative to other industrial products, which synthesized by physical or chemical methods. This high ability of microorganisms to provide the live cells with its elemental needs after modification inside the bio reactors using nuclear fusion, nuclear fission and nuclear adhesion can interpret why microorganism occupy the total environmental system including atmosphere, hydrosphere, rhizosphere and biosphere. This theory can clarify the generation of new elements according to the cell requirements under the catalytic effect of some elements and other ambient factors such as; temperature, humidity, lighting, etc. in a similar way to the bioreactor (cell reactor).

The synthetic genomics and biology aims to model and construct new organisms, biological components and functions which do not exist in nature to meet human needs; or or redesigning existing biological systems for new functionality(Konig et al., 2013). Bloom (2017) identified the usual complex mixtures of chemicals extracted from plants or fruit as natural flavours. There will always be a predominant chemical taste, along with tens to hundreds of other ingredients. This complex mixture provides a deeper, more complex taste to natural extracts. Synthetic flavours generally have only a small number of the same flavor chemicals in the natural extract - mostly one, but the others are missing, so the flavours of the complex mixture can not be duplicated precisely. Thus, while someone who tastes an artificially flavored food can identify the main taste, it can seem tasteless or taste like "there's something missing".

Comparison of synthetic and naturally occurring drugs with particular focus on the nature of the side effects associated with both groups. New drugs for the treatment of complicated diseases are being developed but these drugs are associated with a number of side effects ranging from minor to severe intensity. By contrast, the drugs from nature seem more effective than the synthetic drugs (Nisar et al. 2018).

Finally, it should be noted that scientists could not synthesize chlorophyll and other compounds, which generated in plant cells although its chemical structure is well known by scientists. For example, the central atom of chlorophyll Env. Biodiv. Soil Security Vol. 5 (2021) (magnesium) could be generated using nuclear fusion, nuclear fission and nuclear adhesion in a specific system (ratio and arrangements). This system is well known by the cell but it is still unknown by scientists.

\section{Conclusions}

There is no doubt and certainty that depends on it in all sciences of the universe is the law of survival, the survival of matter, energy, mass, etc. What we all recognize and believe is nothing that was found out of whether or not destined for nonexistence, but anything that can transform from or to and does not disappear. Science has proven that there is a shift of the element from one element to another through fission or nuclear fusion through nuclear reactors, and there is no doubt that there is an unprecedented development in the various branches of physics and chemistry, whether classic or modern or quantum. Also, the reactors did not stop on this, but rather evolved in recent times to include biological reactors that would produce materials by living organisms that are difficult to produce industrially. Hence the idea of research came through which we try to prove that a living cell has the ability to transform elements from one element to another and that this action needs on living cells and this action we called it a cell reactor. Until we get to this idea, bacterial cells were used as living cells to speed their growth and the speed of the results that can be proven. An experiment was conducted on two types of bacteria and the medium in which they intend to change was added by adding elements that would stimulate or inhibit growth. Through the results obtained, it was found that there were elements that increased in the growth medium and other elements decreased, and that there were some elements that disappeared and other elements that appeared that were not present in the medium. This means that some elements have been transformed into other elements, which made them increase, decrease, fade or appear. This result was not only what we reached, but it appeared that the sum of the elements in the different environments changed significantly, despite the fact that they did not disappear as the law stipulates the survival of the material. By analyzing it, identifying it despite its existence is what we call it nuclear adhesion, where the nuclei of atoms are attached to elements in the form of a cluster and not fused, and they are surrounded by electrons that are equivalent to the charge. These elements are produced only inside the cellular 
reactor, that is, in the presence of the living cell. Perhaps these conclusions explain many of the phenomena without which it would have been impossible to reach a logical explanation. Regardless the aforementioned theories (nuclear fusion and nuclear fission), we hypothesize that there is another theory for elements creation through nuclear adhesion. In this theory, two or more nuclei are stacked together and surrounded by electrons to neutralize the whole protons inside nuclei. This theory can be occurred only inside the live cells, which are able to make the nuclear adhesion in the presence of auxiliary factors such as trace elements and environmental conditions (heat, light, humidity, etc.).

\section{Acknowledgments}

Authors would like to acknowledge (i) Soil Fertility and Fertilizers Quality Control, ISO 17025 accredited Lab for elemental analysis, (ii) Electron Microscopy Unit for EDS analysis, and (iii) Agricultural Microbiology Lab (vi) and Agricultural Chemistry Lab, for chemical and microbiological analysis.

\section{Funding}

The authors declare that there is no financial or non-financial conflict of interest in the publication of this manuscript.

\section{Contribution of authors}

AME provided some necessary tools for experiments, experimental instructions, contributed to the interpretation of the results, contributed to the writing and revision of the manuscript. NEE performed some of the experiments, contributed to the interpretation of the results, contributed substantially to the writing and revision of the manuscript. AAM proposed the research concept, provided some necessary tools for experiments, carried out some of the experiments, collected the data and contributed substantially to the writing of the manuscript. AYE proposed the research concept, performed some of the experiments, experimental instructions, contributed to the interpretation of the results and contributed substantially to the writing, reviewing and revision of the manuscript. EMS projected the topic, designed the research plan and performed some of the experiments, experimental instructions, participated in the statistical analysis and coordinated and contributed in writing and critical reviewing of the final manuscript. HMA proposed the research concept, provided some necessary tools for experiments, carried out some of the experiments, collected the data and contributed substantially to the writing of the manuscript. AMES anticipated the topic, designed the research plan and performed some of the experiments, experimental instructions, participated in the statistical analysis and coordinated and contributed in writing and critical reviewing of the final manuscript. All authors read and approved the final manuscript.

\section{Conflict of interest}

There is no any conflict among the authors.

\section{References}

Albanese A,Vicentini M (1997) Why do we believe that an atom is colourless? Reflections about the teaching of the particle model. Science \& Education, 6 (3), 251-261.

Ball P(2002) The ingredients: a guided tour of the elements. Oxford University Press, Oxford, United Kingdom.

Bischof M, Del Giudice E (2013) Communication and the emergence of collective behavior in living organisms: a quantum approach. Molecular Biology International. http://dx.doi. org/10.1155/2013/987549

Bloom J (2017). Natural and Artificial Flavors: What's the Difference? A publication of the, American Council on Science and Health. ISBN: 978-09910055-9-8.

Brar DS, Rambold S, Gamborg O,Constabel F (1979). Tissue culture of corn and sorghum. ZeitschriftfürPflanzenphysiologie, 95, 377-388.

Cao M, Gao M, Suastegui M, MeiY, Shao Z(2020). Building microbial factories for the production of aromatic amino acid pathway derivatives: from commodity chemicals to plant-sourced natural products. Metabolic Engineering, 58, 94-132.

De Laeter JR, Böhlke JK, De Bièvre P, Hidaka H, Peiser HS, Rosman KJR, Taylor PDP (2003). Atomic weights of the elements. Review 2000 (IUPAC Technical Report). Pure and Applied Chemistry, 75 (6), 683-800.

Dekker S(2016) Drift into failure: From hunting broken components to understanding complex systems. CRC Press.

Dethlefsen L, McFall-Ngai M,Relman DA (2007) An ecological and evolutionary perspective on human-microbe mutualism and disease. Nature, 449, 811-818.

Env. Biodiv. Soil Security Vol. 5 (2021) 
Dill-McFarland KA, Tang Z-Z, Kemis JH, Kerby RL, Chen G, Palloni A, Sorenson T, Rey FE, Herd P (2019) Close social relationships correlate with human gut microbiota composition. Scientific Reports, 9, 1-10.

El-Ghamry AM, Mosa AA, Alshaal TA, El-Ramady HR (2018) Nanofertilizers vs. Biofertilizers: New Insights. Environment, Biodiversity and Soil Security, 2, 51-72.

Faust, K., Sathirapongsasuti, J.F., Izard, J., Segata, N., Gevers, D., Raes, J., Huttenhower, C. (2012) Microbial co-occurrence relationships in the human microbiome. PLoScomput biol. 8, e1002606.

Gage DJ (2004) Infection and invasion of roots by symbiotic, nitrogen-fixing rhizobia during nodulation of temperate legumes. Microbiology and Molecular Biology Reviews, 68, 280-300.

Grice EA, Segre JA (2012) The human microbiome: our second genome. Annu Rev Genomics Hum Genet. 13, 151-170.

Gustavsson M, Lee SY (2016) Prospects of microbial cell factories developed through systems metabolic engineering. Microbial Biotechnology, 9, 610-617.

Hofmann S, Ninov V, Heßberger FP, Armbruster P, Folger H, Münzenberg G, Schött HJ, Popeko AG, Yeremin AV, Andreyev AN, Saro S, Janik R, Leino M (1995) The new element 111. Zeitschrift für Physik A Hadrons and Nuclei, 350 (4), 281-282.

Hofmann S (2011) Synthesis of superheavy elements by cold fusion. Radiochim. Acta, 99, 405-428.

Hofmann S, Ninov V, Hessberger FP, Armbruster P, Folger H, Münzenberg G, Schött HJ, Popeko AG, Yeremin AV, Saro S, Janik R (1996) The new element 112. ZeitschriftfürPhysikA Hadrons and Nuclei, 354 (3), 229-230.

Horrobin DF (1971) Isotopes and radioactivity. In: Essential Physics, Chemistry and Biology (pp. 4348). Springer, Dordrecht.

Ireson $\mathrm{G}(2000)$. The quantum understanding of preuniversity physics students. Physics Education, $\mathbf{3 5}$ (1), 15.

Kelly RL, Palumbo LJ (1973) Atomic and ionic emission lines below 2000 angstroms-hydrogen through krypton (No. NRL-7599) Naval Research Lab, Washington DC.

Khazan A (2007) Upper limit of the Periodic Table and synthesis of superheavy elements. Progress in Physics, 2, 104-109.
Kirilyuk AP (2001) 75 Years of the Wavefunction: Complex-Dynamical Extension of the Original Wave Realism and the Universal Schrödinger Equation.arXiv preprint quant-ph/0101129.

Konig H, Frank D, Heil R,Coenen C(2013). Synthetic Genomics and Synthetic Biology Applications Between Hopes and Concerns. Current Genomics, 14 (1), 11-24.

Kumar A, Chordia, N (2017) Role of Microbes in Human Health. Appli Microbiol: Open Access, 3 (2) 131-133. doi:10.4172/2471-9315.1000131

Kumar P, Chander, B (2020) COVID 19 mortality: Probable role of microbiome to explain disparity. Medical Hypotheses 144, 110209.

Lenshof A,Laurell T (2010) Continuous separation of cells and particles in microfluidic systems. Chemical Society Reviews, 39 (3), 1203-1217.

Matthews, M. R. International Handbook of Research in History, Philosophy and Science Teaching. Springer Dordrecht Heidelberg New York London. Library of Congress Control Number: 2013958394 (2014). doi:10.1007/978-94-007-7654-8

Miller RA, Gamborg OL, Keller WA, Kao KN (1971) Fusion and division of nuclei in multinucleated soybean protoplasts. Canad. J. Genet. Cytol. 13, 347-353.

Motoyoshi F (1971) Protoplasts isolated from callus cells of maize endosperm. Exp. Cell Res. 68, 452456.

Najafpour GD (2007) Bioreactor Design, Chapter 6. Biochemical Engineering and Biotechnology, pp. 142-169.

Nisar, B., Sultan, A. \& Rubab, S. L. Comparison of Medicinally Important Natural Products versus Synthetic Drugs-A Short Commentary. Natural Products Chemistry \& Research, 6 (2) 308-309 (2018). DOI: $10.4172 / 2329-6836.1000308$

Pham JV, Yilma MA, Feliz A, Majid MT, Maffetone N, Walker JR, Kim E, Reynolds JM, Song MC (2019) A Review of the Microbial Production of Bioactive Natural Products and Biologics. Frontiers in Microbiology, 10, 1404.

Poulsen T (2010) Introduction to Chemistry. New York: Amazon Company.

Retsky MW (2003) Method and apparatus for deflecting and focusing a charged particle stream. US Patent 6,614,151, Washington, DC: U.S. Patent and Trademark Office.

Env. Biodiv. Soil Security Vol. 5 (2021) 
Romer A (1997) Proton or prouton?: Rutherford and the depths of the atom. American Journal of Physics, 65 (8), 707-716.

Schmidt HJ, Baumgärtner T, Eybe H (2003) Changing ideas about the periodic table of elements and students' alternative concepts of isotopes and allotropes. Journal of Research in Science Teaching, 40 (3), 257-277.

Schröder HC, Wang X, Tremel W, Ushijima H, Müller WE(2008) Biofabrication of biosilica-glass by living organisms. Natural Product Reports, 25 (3), 455-474.

Šmajs $J(2015)$ The philosophical conception of a constitution for the Earth. Human Affairs, 25 (3), 342 .

Tanner G, Richter K, Rost JM (2000) The theory of twoelectron atoms: between ground state and complete fragmentation. Reviews of Modern Physics, 72 (2), 497.
Ursell LK, Clemente JC, Rideout JR, Gevers D, Caporaso JG, Knight R (2012) The interpersonal and intrapersonal diversity of human-associated microbiota in key body sites. Journal of Allergy and Clinical Immunology, 129, 1204-1208.

Wackett LP, Dodge AG, Ellis LBM (2004) Microbial genomics and the periodic table. Applied and Environmental Microbiology, 70, 647-655.

Waters CM,Bassler BL (2005). Quorum sensing: cell to cell communication in bacteria. Annu. Rev. Cell Dev. Biol. 21, 319-346.

Withers LA, Cocking EC (1972) Fine structural studies on spontaneous and induced fusion of higher plant protoplasts. Journal of Cell Science, 11 (1), 59-75.

Woodcock R (1973) Woodcock reading mastery test. Circle Pines, MN: American Guidance Service. 